\title{
A Study of Hormonal Receptors in Esophageal Carcinoma: Northeast Indian Tertiary Cancer Center Study
}

\author{
Deepjyoti Kalita ${ }^{1}$ Srinivas Bannoth ${ }^{1} \quad$ Joydeep Purkayastha ${ }^{1}$ Abhijit Talukdar ${ }^{1}$ Gaurav Das ${ }^{1}$ \\ Pritesh Singh ${ }^{1}$
}

${ }^{1}$ Department of Surgical Oncology, Dr. Bhubaneswar Borooah

Cancer Institute, Guwahati, Assam, India

\begin{abstract}
Address for correspondence Srinivas Bannoth, Mch Surgical Oncology, Department of Surgical Oncology, Dr. B. Borooah Cancer Institute, A.K. Azad Road, Gopoinath Nagar, Guwahati, Assam, 781016, India (e-mail: srinivasbannoth@gmail.com).
\end{abstract}

South Asian J Cancer 2021;9:222-226.

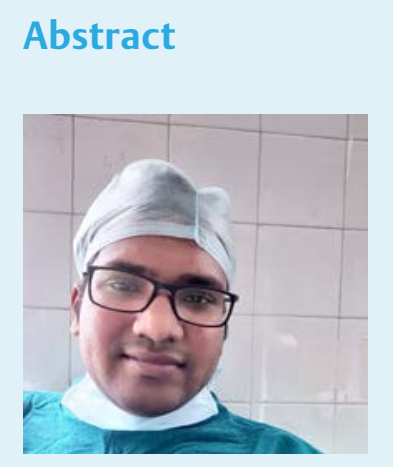

Dr. Srinivas Bannoth

Keywords

- carcinoma esophagus

- estrogen receptors

- progesterone receptors
Background Esophageal cancers, both squamous cell and adenocarcinoma, have poor outcomes with high morbidity and mortality. Our hospital-based registry for the year 2017 to 2018 showed that esophageal cancer constituted $22.7 \%$ of annual caseload. Most of our patients present in advanced stages. The aim of this article was to study the role of hormonal receptors in patients with esophageal cancer.

Methods This is a single-institution, prospective, observational study in patients with esophageal carcinoma. Hormonal receptors (estrogen receptor [ER]- $\alpha$ and progesterone receptors) were studied in tumor tissue. Of 160 patients, receptor status was analyzed in 133 patients. Chi-square test was used for the correlation of categorical variables. The value of $p<0.05$ was considered as statistically significant.

Results A total of 133 patients was taken into the study of which 96 were males and 37 were females. The mean age of patients was 52 years. Carcinoma esophagus was predominantly seen in males. Estrogen and progesterone receptors were positive in 9.02 and $4.51 \%$ of the study population, respectively. Patients with hormonal receptor positivity presented with poor functional status, higher grades of dysphagia, higher stage, and most of the tumors were poorly differentiated with statistically significant $p$-values.

Conclusion Despite recent advances in various fields of oncology, outcomes of esophageal carcinoma have not improved significantly. Hence, a study of new pathways of pathogenesis in carcinogenesis of esophageal carcinoma is essential. Few recent evidences including our study shows that the hormonal milieu is responsible in the pathogenesis of carcinoma esophagus. The utilization of this data and future study of the role of hormonal therapy might lead to improved outcomes in patients with carcinoma esophagus.
DOI https://doi.org/10.1055/s-0041-1729448 ISSN 2278-330X

How to cite this article: Kalita D, Bannoth S, Purkayastha J, Talukdar A, Das G, A Study of Hormonal Receptors in Esophageal Carcinoma: Northeast Indian Tertiary Cancer Center Study Singh P. South Asian J Cancer 2021;9(4):222-226.
(C) 2021. MedIntel Services Pvt Ltd.

MedIntel Services Pvt Ltd.. This is an open access article published by Thieme under the terms of the Creative Commons Attribution-NonDerivative-NonCommercial-License, permitting copying and reproduction so long as the original work is given appropriate credit. Contents may not be used for commercial purposes, or adapted, remixed, transformed or built upon. (https://creativecommons.org/licenses/by-nc-nd/4.0/). Thieme Medical and Scientific Publishers Private Ltd A-12, Second Floor, Sector -2, NOIDA -201301, India 


\section{Introduction}

Esophageal cancers, both squamous cell and adenocarcinoma, have poor outcomes with high morbidity and mortality. Global cancer statistic 2018 ranks esophageal cancer as the seventh most common cancer in terms of percentage incidence of new cases site. Over 572,034 (3.2\%) new cases were reported and registered number of deaths was 508,585 (5.3\%) of all sites. ${ }^{1}$ It is expected that by 2025 , incidence of esophageal cancer is expected to rise by $140 \%{ }^{2}$ Our hospital-based registry for the year 2017 to 2018 showed that esophageal cancer constituted $22.7 \%$ of the annual caseload.

Squamous cell carcinoma and adenocarcinoma are the two main histopathological types. ${ }^{3}$ Estrogen through regulation of adipose tissue of the body and fat distribution is associated with increase in risk for esophageal adenocarcinoma. ${ }^{4,5}$ There is a lack of sufficient data on the role of the presence of hormonal receptors in esophageal carcinoma which could be a target of therapy.

In view of high esophageal cancer, load, and most patients presenting in the advanced stage, we want to study the role of estrogen and progesterone receptors in esophageal cancer patients.

\section{Methods}

This is a single-institution, prospective, observational study in patients with esophageal carcinoma, conducted by the Department of Surgical Oncology at Dr. Bhubaneswar Borooah Cancer Institute, Guwahati, Assam, India. The study period was from August 12, 2018, to September 5, 2019. A total of 160 patients was taken into the study, but data regarding only 133 patients were analyzed as the rest of the patients lost to follow-up in the initial evaluation phase. Data regarding clinical features, diagnostic and staging workup, and hormonal receptor status were collected from patient history and hospital records.

SSPS (Statistical Package for the Social Sciences IBM Corp, Chicago, USA) software, version 2017 was used. Chi-square test was used for the correlation of categorical variables. Value of $p<0.05$ was considered as statistically significant.

The workup for all patients included a detailed history; physical examination; standard blood workup; upper gastrointestinal biopsy; and contrast-enhanced computed tomography of the neck, chest, and abdomen. On an average, five samples of tumor tissue from the different location were taken. The staging was done according to the eighth edition of the American joint committee on Cancer for esophageal cancer. Dysphagia score was graded as grade-1: able to swallow some solids, grade-2: able to swallow only semisolids, grade-3: able to swallow liquids only, and grade-4: unable to swallow anything or total dysphagia. Functional status of patients was assessed according to the Eastern Cooperative Oncology Group (ECOG) score as ECOG-0 as fully active and able to carry all predisease activity. Grade-1: able to carry out light household work, grade-2: unable to carry out any activities and about $>50 \%$ waking hours, grade- 3 : capable of limited self-care and confined to chair $>50 \%$ of waking hours, grade-4: completely disabled, and grade-5: dead.
Immunohistochemistry (IHC) for estrogen receptor (ER)- $\alpha$ and progesterone receptors has been performed on deparaffinized, formalin-fixed paraffin-embedded tissues ( - Fig. 1). IHC was done by the manual method using cell mark Specific Protein -1 (SP-1) clone (rabbit monoclonal) for ER- $\alpha$ and Y85 (rabbit monoclonal) clone for progesterone receptor staining . The reporting of positive staining for both ER- $\alpha$ and progester - one receptor was done based on the percentage of cells with nuclear positivity of weak, moderate, or strong intensity in $>1 \%$ of tumor cells taking breast slide as control.

\section{Results}

A total of 133 patients were taken into the study of which 96 were males and 37 were females. The mean age of patients was 52 years. The mean hemoglobin of patients was $9.3(\mathrm{~g} / \mathrm{dL})$, and the mean albumin was $3.2(\mathrm{~g} / \mathrm{dL})$. Around 74 patients presented with ECOG-1 functional status, 44 patients had ECOG-2 status, and ECOG-3 status in 15 patients (- Table 1 ).

Dysphagia grades 1, 2, 3, and 4 were seen in 28.6, 40.6, 24.8, and $6 \%$ of patients, respectively (- Table 1 ). Histopathological analysis showed 116 patients with squamous cell carcinoma, 13 patients with adenocarcinoma, and adenosquamous cell carcinoma, signet-ring cell carcinoma, and neuroendocrine
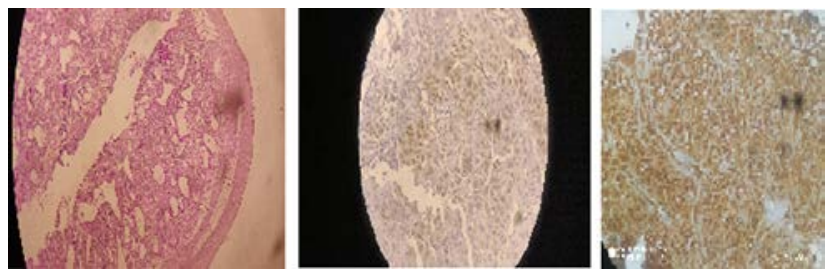

Fig. 1 Histopathology and immunohistochemistry slide of carcinoma esophagus with estrogen- and progesterone-receptor positivity.

Table 1 Demographic, clinical presentation data of patients $(n=133)$

\begin{tabular}{|l|l|}
\hline Characteristics & $\boldsymbol{n}(\%)$ \\
\hline Gender & \\
\hline Male & $96(72.2)$ \\
\hline Female & $37(27.8)$ \\
\hline Mean hemoglobin $(\mathrm{g} / \mathrm{dL})$ & 9.3 \\
\hline Mean albumin $(\mathrm{g} / \mathrm{dL})$ & 3.2 \\
\hline ECOG status & \\
\hline 1 & $74(55.6)$ \\
\hline 2 & $44(33.1)$ \\
\hline 3 & $15(11.3)$ \\
\hline Dysphagia grades & \\
\hline 1 & $38(28.6)$ \\
\hline 2 & $54(40.6)$ \\
\hline 3 & $33(24.8)$ \\
\hline 4 & $8(6)$ \\
\hline
\end{tabular}

Abbreviation: ECOG, Eastern Cooperative Oncology Group. 
Table 2 Histopathology and stage of patients $(n=133)$

\begin{tabular}{|l|l|}
\hline Characteristics & $\boldsymbol{n}(\%)$ \\
\hline Histology & \\
\hline Squamous cell carcinoma & 116 \\
\hline Adenocarcinoma & 13 \\
\hline Adenosquamous & 2 \\
\hline Neuroendocrine carcinoma & 1 \\
\hline Signet ring cell carcinoma & 1 \\
\hline Grade & \\
\hline Well differentiated & $32(24.1)$ \\
\hline Moderately differentiated & $87(65.4)$ \\
\hline Poorly differentiated & $14(10.5)$ \\
\hline Stage & \\
\hline I & $11(8.3)$ \\
\hline II & $69(51.9)$ \\
\hline III & $44(33.1)$ \\
\hline IVA & $2(1.5)$ \\
\hline IVB & $7(5.3)$ \\
\hline
\end{tabular}

Table 3 Hormonal receptor status $(n=133)$

\begin{tabular}{|l|l|}
\hline Characteristics & $\boldsymbol{n}(\%)$ \\
\hline ER- $\alpha$ clone & \\
\hline Positive & $12(9.02)$ \\
\hline PR & \\
\hline Positive & $6(4.51)$ \\
\hline
\end{tabular}

Abbreviations: ER, estrogen receptor; PR, progesterone receptor.

carcinoma in 2, 1, and 1 patients, respectively. Grades of differentiation included well-differentiated adenocarcinoma in $24.1 \%$ of patients, moderately differentiated in $65.4 \%$ of patients, and poorly differentiated in $10.5 \%$ of patients (-Table 2).

Stages of patients according to tumor-node metastasis (TNM) eighth edition include stages I, II, III, IVA, and IVB in 8.3, $51.9,33.1,1.5$, and 5.3\%, respectively (- Table 2 ). ER- $\alpha$ clone was analyzed in esophageal tumor tissue; of 133 patients, ER was positive in 12 (9.02\%) patients. Progesterone receptors were positive in six $(4.51 \%)$ of the study population (- Table 3).

Correlation of various factors related to ER and progesterone receptor positivity was done. ER positivity was seen more in male patients, with a male-to-female ratio of $2: 1$ $(p=0.655)$, whereas progesterone receptor positivity showed male-to-female ratio of $1: 1(p=0.347)$. In patients with ER positivity, around $75 \%$ of patients presented with initial functional status of ECOG-2 and above $(p=0.001)$, whereas in patients with progesterone receptor positivity around $83.3 \%$ presented with functional status of ECOG-3 $(p=0.000$; - Table 4). Correlation of dysphagia scores with receptor positivity showed dysphagia grade of 3 and above in $83.3 \%$ with estrogen and progesterone receptor positivity ( $p=0.000 ;$-Table 4).

When pathological grade was correlated with receptor positivity, ER positivity had grades of well-differentiated, moderately differentiated, and poorly differentiated tumors in $8.3,33.3$, and $58.3 \%$, respectively $(p=0.000$ ), whereas patients with progesterone receptor positivity had 16.7, 16.7, and $66.7 \%$, respectively, $(p=0.000)$. Stage-wise correlation of patients with ER positivity for stages I, II, III, IVA, and IVB was $0,8.3,50,16.7$, and $25 \%$, respectively $(p=0.000)$, and for patients with progesterone receptor positivity was $0,16.7$, $33.3,16.7$, and $33.3 \%$, respectively ( $p=0.000$; - Table 4 ).

\section{Discussion}

Esophageal cancers, both squamous cell and adenocarcinoma, have poor outcomes with high morbidity and mortality. Our hospital-based registry for the year 2017 to 2018 showed that esophageal cancer constituted $22.7 \%$ of the annual caseload. Global cancer statistic 2018 ranks esophageal cancer as the seventh most common cancer in terms of percentage incidence of new case sites. Over 572,034 (3.2\%) new cases were reported, and the registered number of deaths was 508,585 (5.3\%) of all sites. ${ }^{1}$

Esophageal squamous cell carcinoma and adenocarcinoma constitute two major histological types with differences in the prevalence of both according to geographical variation. ${ }^{6}$ Different modalities of treatment include surgical resection, definitive chemoradiotherapy, and palliation with the best supportive care for patients who present in late stages. ${ }^{7}$ Although there are advances in various fields of oncology and multidisciplinary approach, most of the patients with esophageal carcinoma, present in advanced stage outcomes, still remain poor. ${ }^{8}$

As current treatment modalities have not led to significant outcomes, the study of new means of approaches with understanding of factors or pathways associated with the disease process and introduction of new treatment measures, which can lead to improved outcomes in patients with esophageal carcinoma, is of utmost need.

Influence of hormonal milieu on pathogenesis of esophageal carcinoma though has been studied, very limited data exit in literature regarding this and no conclusive outcomes has been established yet, in view of high burden of esophageal cancer in the Northeastern part of India, we wanted to study effect of hormonal linkage in our set of esophageal cancer patients.

ER is a type of steroid receptor class of nuclear receptor superfamily. The effect of estrogen is predominantly mediated through ER- $\alpha$ and ER- $\beta$ isoforms. ${ }^{9-11}$

Demographic data from our study show that around $72.2 \%$ of patients were males, which suggests some hormonal milieu might be involved apart from common risk factors for esophageal carcinoma pathogenesis. Due to nonavailability of reagent for ER- $\beta$ and cost issues, only ER- $\alpha$ isoform was analyzed in our patients. There are limited data regarding the immunohistochemical expression of estrogen- $\alpha$ and 
Table 4 Characteristics of patients with hormonal receptor positivity

\begin{tabular}{|c|c|c|c|c|}
\hline Characteristics & $\begin{array}{l}\text { ER- } \alpha \text { positive }(n=12) \\
n(\%)\end{array}$ & $p$ & $\begin{array}{l}\text { PR positive }(n=6) \\
n(\%)\end{array}$ & $p$ \\
\hline \multicolumn{5}{|l|}{ Sex } \\
\hline Male & 8 & 0.655 & 3 & 0.347 \\
\hline Female & 4 & 0.737 & 3 & 0.347 \\
\hline \multicolumn{5}{|l|}{ ECOG status } \\
\hline 1 & $3(25)$ & 0.001 & $1(16.7)$ & 0.00 \\
\hline 2 & $4(33.3)$ & 0.001 & 0 & 0.00 \\
\hline 3 & $5(41.7)$ & 0.001 & $5(83.3)$ & 0.00 \\
\hline \multicolumn{5}{|l|}{ Dysphagia grade } \\
\hline 1 & 0 & 0.000 & 0 & 0.000 \\
\hline 2 & $2(16.7)$ & 0.000 & $1(16.3)$ & 0.000 \\
\hline 3 & $6(50)$ & 0.000 & $2(33.3)$ & 0.000 \\
\hline 4 & $4(33.3)$ & 0.000 & $3(50)$ & 0.000 \\
\hline \multicolumn{5}{|l|}{ Pathological grade } \\
\hline Well differentiated & $1(8.3)$ & 0.000 & $1(16.7)$ & 0.000 \\
\hline $\begin{array}{l}\text { Moderately } \\
\text { differentiated }\end{array}$ & $4(33.3)$ & 0.000 & $1(16.7)$ & 0.000 \\
\hline Poorly differentiated & $7(58.3)$ & 0.000 & $4(66.7)$ & 0.000 \\
\hline \multicolumn{5}{|l|}{ Stage } \\
\hline 1 & 0 & 0.000 & 0 & 0.000 \\
\hline II & $1(8.3)$ & 0.000 & $1(16.7)$ & 0.000 \\
\hline III & $6(50)$ & 0.000 & $2(33.3)$ & 0.000 \\
\hline IVA & $2(16.7)$ & 0.000 & 1 (16.7) & 0.000 \\
\hline IVB & $3(25)$ & 0.000 & $2(33.3)$ & 0.000 \\
\hline
\end{tabular}

Abbreviations: ECOG, Eastern Cooperative Oncology Group; ER, estrogen receptor, PR, progesterone receptor.

estrogen- $\beta$ isoforms. A study by Nozoe et al showed that an inverse relationship exists between the expression of ER- $\alpha$ and ER- $\beta$ receptor isoforms, ${ }^{12}$ whereas studies of Kalayarasan et al did not report any expression of ER- $\alpha$ isoform. ${ }^{13}$ Analysis of our data from 133 patients of esophageal carcinoma has shown ER- $\alpha$ isoform positivity in $9.02 \%$ of patients. Our set of patients showed positivity for ER- $\alpha$ isoform, as seen in studies of Nozoe et al. Data regarding progesterone receptor positivity have not shown any conclusive results yet. Our study has shown a progesterone receptor positivity of $6 \%$.

Correlation of various factors has been done with hormonal receptor positivity. The male-to-female ratio of receptor positivity for $E R-\alpha$ isoform was 2:1, while the same for progesterone receptor positivity was $1: 1$ with nonsignificant $p$-value. When compared with patients with receptor-negative status, most of the patients with hormonal receptor positivity presented with poor functional score, with statistically significant $p=0.001$ and 0.00 for ER- $\alpha$ and progesterone receptor positivity, respectively.

Correlation of dysphagia scores for ER- $\alpha$ and progesterone receptor positivity showed that most of the patients whose receptor status was positive presented with higher dysphagia grades with statistically significant $p$-value $(p=0$. 000 ). When correlation was done with pathological grade of tumors, it was observed that among patients with hormonal receptor positivity, both for ER- $\alpha$ and progesterone receptors, signifi - cant number of patients was poorly differentiated with statis - tically significant $p$-value $(p=0.000)$. When hormonal receptor positivity was correlated with the stage of presentation of car-cinoma in accordance with AJCC ( American Joint Committee on Cancer) TNM eighth edition, most of the patients presented with stage III and above with statistically significant $p$-value.

In view of the major bulk of carcinoma esophagus in our part of the country with annual new case registration of $22.7 \%$ of hospital load, it is of utmost importance for us to find new pathways of linkage for the pathogenesis of esophageal carcinoma to improve outcomes in our patients. This study is such an attempt. In the current study, the positivity of ER- $\alpha$ receptor has been observed in $9.02 \%$ of patients. Based on the above background, we are planning to study even ER- $\beta$ isoforms and a pilot study to see feasibility and outcomes of hormonal therapy in patients with carcinoma esophagus which may improve outcomes in patients with esophageal carcinoma. 


\section{Strengths and Limitations}

The advantages of our study are, it is a prospective study, and it is the only study till date in our literature search with data of the highest number (133) of patients studied to see the role of hormonal receptor status in carcinoma esophagus. Disadvantages of our study are, we could not study the expression of ER- $\beta$ isoform which showed positivity in previous studies due to logistical issues.

\section{Conclusion}

Despite recent advances in various fields of oncology, outcomes of esophageal carcinoma have not improved significantly. Hence, a study of new pathways of pathogenesis in carcinogenesis of esophageal carcinoma is essential. Few recent evidences, including our study, show that hormonal milieu is responsible for the pathogenesis of carcinoma esophagus, utilization of this data, and future study of the role of hormonal therapy that might lead to improved outcomes in patients with carcinoma esophagus. Further large-scale studies are required to confirm these results.

\section{Funding}

Nil.

\section{Conflicts of Interest}

There are no conflicts of interest to declare.

\section{Acknowledgments}

The authors would like to thank all of our patients, all departments of Dr. Bhubaneswar Borooah Cancer Institute.

\section{References}

1 Bray F, Ferlay J, Soerjomataram I, Siegel RL, Torre LA, Jemal A. Global cancer statistics 2018: GLOBOCAN estimates of incidence and mortality worldwide for 36 cancers in 185 countries. CA Cancer J Clin 2018;68(6):394-424

2 Lambert R, Hainaut P. The multidisciplinary management of gastrointestinal cancer. Epidemiology of oesophagogastric cancer. Best Pract Res Clin Gastroenterol 2007;21(6):921-945

3 Young JL Jr, Percy CL, Asire AJ, et al. Cancer incidence and mortality in the united states, 1973-77. Natl Cancer Inst Monogr $1981 ;(57): 1-187$. PMID:7278952.

4 Clegg DJ, Brown LM, Woods SC, Benoit SC. Gonadal hormones determine sensitivity to central leptin and insulin. Diabetes 2006;55(4):978-987

5 Lagergren J, Nyrén O. Do sex hormones play a role in the etiology of esophageal adenocarcinoma? A new hypothesis tested in a population-based cohort of prostate cancer patients. Cancer Epidemiol Biomarkers Prev 1998;7(10):913-915

6 Hongo M, Nagasaki Y, Shoji T. Epidemiology of esophageal cancer: Orient to Occident. Effects of chronology, geography and ethnicity. J Gastroenterol Hepatol 2009;24(5):729-735

7 Mariette C, Piessen G, Triboulet JP. Therapeutic strategies in oesophageal carcinoma: role of surgery and other modalities. Lancet Oncol 2007;8(6):545-553

8 Lee PC, Port JL, Paul S, Stiles BM, Altorki NK. Predictors of long-term survival after resection of esophageal carcinoma with nonregional nodal metastases. Ann Thorac Surg 2009;88(1):186-192, discussion 192-193

9 Deroo BJ, Korach KS. Estrogen receptors and human disease. J Clin Invest 2006;116(3):561-570

10 Mosselman S, Polman J, Dijkema R. ER beta: identification and characterization of a novel human estrogen receptor. FEBS Lett 1996;392(1):49-53

11 Delaunay F, Pettersson K, Tujague M, Gustafsson JA. Functional differences between the amino-terminal domains of estrogen receptors alpha and beta. Mol Pharmacol 2000;58(3):584-590

12 Nozoe T, Oyama T, Takenoyama M, Hanagiri T, Sugio K, Yasumoto K. Significance of immunohistochemical expression of estrogen receptors alpha and beta in squamous cell carcinoma of the esophagus. Clin Cancer Res 2007;13(14):4046-4050

13 Kalayarasan R, Ananthakrishnan N, Kate V, Basu D. Estrogen and progesterone receptors in esophageal carcinoma. Dis Esophagus 2008;21(4):298-303

\section{Covid-19 and Cancer - Virtual Expert Board}

Every Tuesdays and Thursdays at 7:30 pm sharp on Zoom

Program Directors - Dr Amish Vora, Dr TP Sahoo, Dr Purvish M Parikh

Expert Board Series Managers - Kavina Creations

kashish@kavinacreations.com 9819025850 